\title{
CLASIFICACION DE BIENES MUEBLES E INMUEBLES
}

\author{
Humberto Jara Flórez
}

Con una especie de prestigio inalterable, como si fuera un monarca coronado universalmente que visita sus feudos encontrando invariablemente los designios de su voluntad, la clasificación de Bienes Muebles y Bienes Inmuebles ha venido siendo durante siglos, la opción legislativa acogida por casi todos los Códigos Civiles del mundo. Todos han rendido pleitesía y otorgado respaldo a esta clasificación milenaria.

Precisamente por esa antiguedad interesa saber si aún es válida, qué virtudes o qué defectos posee. El sentido de este trabajo es encontrar una respuesta a estas interrogantes.

Si bien la clasificación de Bienes en muebles e inmuebles viene de muy antiguo, su importancia no ha sido siempre la misma. Acogida por el Derecho en Roma era apenas "una subdivisión de las cosas materiales o bienes corporales. Asi es como la entendian los jurisconsultos romanos, para los cuales, además, no tenía más que una pequeña importancia práctica, por aplicarse en principio las mismas reglas a la propiedad mueble y a la inmueble" (1).

(1) Colin, Ambrosio y Capitant, Henri, Curso Elemental de Derecho Civil, tomo Segundo, vol. II, Ed. Reus, Madrid 1923, p. 465. 
En esta época "el criterio de la distinción residia únicamente en la naturaleza de las cosas: eran inmuebles el suelo y las construcciones, cosas no susceptibles de traslado, res inmóviles; todas las demás cosas eran mobiliarias. Los romanos jamás pensaron en extender esa clasificación a los derechos ni siquiera a los derechos reales" (2).

Fue más tarde, en el antiguo Drrecho Francés inmediatamente después de la Edad Media que esta clasificación se convirtió en la summa divissio.

En la época medieval los inmuebles, especificamente la tierra, tenian gran importancia, la misma que se traducia en términos políticos y económicos, pues, políticamente la jerarquía de las personas guardaba estricta relación con las extensiones territoriales de que podian ser dueñas $y$, paralelamente, la economía familiar y por tanto su status social dependian de la única fuente de riqueza: la propiedad territorial, los feudos.

Asi las cosas, es comprensible que el antiguo Derecho Francés*, todavia influenciado por las ideas feudales, elaborase un sistema basado en la protección a la riqueza inmobiliaria. De este modo, por ejemplo, los inmuebles debian permanecer siempre en la familia originalmente propietaria no pudiendo el testador disponer con libertad de ellos; 0 , en el régimen matrimonial, los inmuebles no ingresaban en la comunidad de bienes.

Como éstas habian muchas reglas que no se aplicaban a los muebles, que por su poca importancia, es decir su poco valor, no merecían mayor atención. De ahi esa vieja frase: "Res movilis, res vilis", que reflejaba la falta de atención al patrimonio mobiliario. En este punto reparemos en algo importante. El criterio para clasificar no fue el usado en Roma. El antiguo Derecho francés excluyó la posibilidad de movimiento o fijeza para atribuir a una cosa la

(2) MAzeaud, Henri, León y Jean, Lecciones de Derecho Civil, Parte Primera, vol. I, Ed. Ejea, Buenos Aires, 1962, p. 283.

* Vamos a referirnos frecuentemente al Derecho francés porque a partir de él la clasificación que distingue entre muebles e inmuebles alcanzó gran notoriedad y aceptación. 
calidad de mueble o inmueble, y prefirió utilizar un criterio económico.

Si a los inmuebles se les prestó tanta atención ello se debió fundamentalmente a su valor, a su duración y a su posiblidad de producir rentas periódicamente.

Al finalizar la Edad Media aparecieron riquezas nuevas que no eran inmuebles y cuyas características encajaban en el criterio económico que acabamos de mencionar, lo que motivó que los juristas, con un criterio más bien práctico, recurrieran a la ficción: como las reglas para los inmuebles eran mayores y más protectivas, convirtieron a ciertos muebles, que tenian las mismas caraterísticas económicas que la tierra, en inmuebles, para que pudieran beneficiarse de un sistema legal mejor estructurado.

"Fue pues, sobre este criterio económico, mucho más que sobre el tomado de la naturaleza de las cosas, sobre el que fundaron su clasificación" (3).

De esta manera edificaciones de poco valor se consideraban como muebles y, viceversa, algunas cosas muebles de valor apreciable pasaron a ser consideradas... inmuebles. Interesaba sobre todo que una determinada cosa tuviera los requisitos de valor, duración y periodicidad de rentas; con estos elementos se podia discriminar y otorgar la calidad de mueble o inmueble.

Esta conceptualización irremediablemente llevó a considerar a los derechos. Si éstos eran capaces de tener (o carecer según sea el caso) las características ya señaladas, era plausible entender que la clasificación también debia incluirlos, pese a que el asunto, desde el punto de vista romano, carecía de sentido pues un derecho no tiene ni movilidad ni fijeza; no obstante, con el criterio económico del antiguo Derecho francés la distinción sí podia alcanzar a un derecho y se le podia aplicar el régimen de los muebles o de los inmuebles. Asi, los créditos se consideraron como muebles porque al existir la prohibición de préstamos con interés esos créditos no producian rentas; por el contrario. los censos o rentas que sí otorgaban réditos se consideraron como in-

(3) MAZEAUD, op. cit. p. 284. 
muebles; igualmente los oficios enajenados que consistian en cargos públicos susceptibles de herencia y aún de venta.

Aunque usaron la etiqueta de "muebles o inmuebles" el criterio en ésta época fue, como ya dijimos, económico.

El Código Civil Fránces. Seguir los rastros de la evolución de esta clasificación nos lleva a mencionar el famoso Código Civil Francés, el Code Napoleónico de 1804, cuerpo legal desde el que la división entre muebles e inmuebles adquirió carta de ciudadania universal, presencia repetida en casi todas las legislaciones occidentales.

Los Mazeaud indican que "los redactores del Código Civil volvieron a la distinción romana, fundada únicamente sobre la naturaleza física de las cosas, por parecerles más lógico el criterio de fijeza o de movilidad" (4).

No obstante esto que parecería un retorno a un criterio más estricto, concordante, además, con la nomenclatura de la clasificación, no fue así; por el contrario, incurrieron en dos defectos: "continúan colocando los derechos, lo mismo que las cosas, en la clasificación cuando el criterio de fijeza no puede aplicarse a los derechos (...) por otra parte -y aqui está su mayor error- conservan todas las diferencias que el antiguo derecho habia establecido entre las reglas de ambas categorias fundadas en el criterio extraido del valor.

Antes de la Revolución, el adagio "res mobilis res vilis" significaba que las cosas sin valor eran muebles, aún cuando fueran inmóviles; y que las cosas de valor eran inmuebles aunque fueran móviles. Los redactores del Código Civil invirtieron esa proposición: para ellos, todas las cosas móviles eran tratadas como si no tuvieran valor alguno; si no las protegian eran porque, a sus ojos, carecian de valor o asi se presumia. Los redactores del Códjgo Civil no se dieron cuenta del defecto fundamental de su sistema: dejaban sin protección cosas y derechos de valor considerable" (5).

(4) MAZEAUD. op. cit. p. 286.

(5) MAZEAUD, op. cit. p. 287. 
Es asi como ha llegado hasta nuestros días esta vieja y prestigiosa clasificación, con sus antiguos defectos acogidos por las legislaciones posteriores a 1804.

\section{CRITICA DE LA CLASIFICACION}

Con el correr del tiempo y aún desde su inicio, la división entre cosas muebles y cosas inmuebles, ha ido mostrando sus amplias deficiencias a medida que las instituciones juridicas iban enfrentando los requerimientos de las relaciones económicas. En la doctrina, a pesar de los devotos de la antiguedad y la tradición, ha quedado planteada la interrogante respecto de la validez de esta clasificación. El tratadista francés Louis Josserand expone de manera exacta el conflicto al afirmar que "con la Revolución (francesa) estas ideas de otra edad tuvieron que ser barridas por la gran corriente individualista que inspiró la Declaración de los Derechos del Hombre y del Ciudadano; sin embargo nada de eso ocurrió pues la distinción entre bienes muebles $e$ inmuebles ha conservado en nuestro Código Civil, casi toda su antigua importancia; es éste uno de los puntos más débiles de la obra del Primer Cónsul, una de su facetas más discutidas. Cada vez más se marca el anacronismo..." y añade "El derecho de los bienes establecido por el Código Napoleón está caducado (...) en pleno siglo $\mathrm{XX}$ vivimos todavia bajo el signo del viejo derecho quiritario" (6).

Sin embargo, pese a criticas tan vigorosa, diversas legislaciones, cobijadas a la sombra del Código Civil francés, han venido usando la clasificación mencionada. Con todo ni su antiguedad ni su uso repetido, le han convalidado los defectos de que padece, y que pasamos a analizar.

a) La evolución histórica denota un errático uso de la clasificación, pues, ha venido siendo utilizada en cada época de acuerdo a criterios distintos. En Roma la distinción radicaba en un criterio de movilidad corespondiente a la caracteristica física de las

(6) Josserand, Louis, Derecho Civil, La Propiedad, vol. III, Buenos Aires 1950 , p.p. 4 y 9. 
cosas; la Edad Media mantiene esencialmente esa distinción; luego en el antiguo derecho francés se usa un raciocinio vinculado al contenido económico de los bienes para luego retornar, ya en el siglo XIX, a la idea romana con el añadido de "convertir" en mueble $O$ inmueble a los derechos.

En suma, a lo largo de miles de años no ha existido una coherencia y una racionalidad propia de esta clasificación. El nombre es apenas una etiqueta que no corresponde al contenido, y sin embargo mezclando criterios y de acuerdo a las conveniencias o requerimientos de cada época sigue siendo incluída en los ordenamientos legales; algo asi como si se quisiera descubrir nuevos continentes remendando la vieja carabela en que navegó Cristóbal Colón.

b) Basada en razones politicas y económicas que hacian que el patrimonio de las personas se sustentara en la propiedad inmobiliaria, la clasificación trajo consigo una marcada protección legal a los inmuebles desamparando a la fortuna mobiliaria. Esas razones tuvieron validez en una época determinada en la que pocos hombres concentraban para si grandes extensiones territoriales $y$ se batian en guerras eternas protegiendo la vastedad de sus feudos y sus ideas contrarias al devenir y progreso de la humanidad.

"Hubo un tiempo en que los inmuebles formaban la porción más preciosa del patrimonio de los ciudadanos y ese tiempo no es quizá aquel en que las costumbres han sido las menos sanas. Pero, luego que las comunicaciones se han vuelto más activas, más fáciles, más amplias y acercado entre si a los hombre de todas las naciones, desde que el comercio ha hecho, por decirlo asi, la producción de todos los paises común a todos los pueblos, ha dado poderosos resortes a la industria, y ha creado nuevas diversiones, es decir, nuevas necesidades, y quizás vicios nuevos, la fortuna mobiliaria de los ciudadanos no ha podido ser extraña ni a las costumbres ni a la legislación" (7).

(7) TREILHARD cit. por Mazeaud, op. cit. p. 287. 
Pese a ello, desde hace mucho tiempo los bienes muebles, debido a la clasificación que les corresponde, no tienen un amparo legal idóneo, los legisladores del Código Civil francés que influenció al mundo entero y los legisladores que después fueron encandilados por dicha ley, no se percataron de "el prodigioso desarrollo del comercio y la industria... (iniciado) en el siglo XIX que ha dado a la propiedad mueble $\mathrm{y}$, más especialmente, a los créditos que afectan la forma de títulos y de valores, una importancia desconocida en otro tiempo" (8). Los diversos Códigos Civiles, entre ellos el peruano, redactados en un tiempo en que las sociedades y sus diversos mecanismos han venido evolucionando constantemente, trayendo, con mayor asiduidad, al comercio mayoritario las cosas muebles que son objeto de un intercambio más contínuo, esos Códigos siguen cometiendo "el error de conservar numerosos vestigios de la antigua idea Res movilis, res vilis. Han acumulado medidas de protección para la fortuna inmueble pero han desdeñado en general preocuparse de los muebles con la misma atención" (9).

Con imperdonable omisión no se han percatado de un aspecto sustancial sobre el que llama la atención Planiol: " La riqueza mueble se cuenta actualmente por millones y probablemente es superior a la riqueza inmueble. Los papeles han cambiado. El axioma "res movilis, res vilis" ha dejado de ser verdadero. ¿Qué es la riqueza inmueble de un señor feudal que percibia rentas sobre algunas parroquias, ante los capitales acumulados en nuestras casas de banca, y en nuestras grandes sociedades de industria o de comercio?". De ahi que este autor considere que los cuerpos legales que conservan "sus antiguas tendencias, se encuentran en desacuerdo con los hechos (...) y cosa curiosa aún el Legislador más moderno sufre a su vez la influencia de la vieja tradición consuetudinaria" (10) que desampara a la propiedad mueble sin razón alguna.

(8) Colin y Capitant, op. cit. p. 467.

(9) COLIN y CAPITANT, op. cit. p.p. 467 y 468.

(10) PLANIOL, Marcel, Tratado Elemental de Derecho Civil, Los Bienes, Ed. Cajica S. A., México 1955 , p. 39. 
Este es uno de los mayores lastres de esta milenaria clasificación, que en honor a su propia antiguedad debia pasar a los archivos de la doctrina jurídica. No es que sea per-se mala, lo que pasa es que correspondió a épocas y circunstancias que no son las nuestras.

c) Produce dos regimenes distintos, uno mejor estructurado para los inmuebles, otro menor para los muebles. Esto que fue válido en el medioevo es inadmisible hoy por las razones expuestas en el acápite b). Veamos esos regimenes.

- La seguridad de las adquisiciones, es diferente en uno y otro caso.

El propietario de un inmueble tiene siempre el derecho de reivindicarlo del adquirente, cuando la enajenación se ha efectuado sin su consentimiento. Para evitar la inseguridad de todo adquirente ante la posibilidad mencionada, la ley ha creado la publicidad tanto para las enajenaciones de inmuebles como para la constitución de derechos reales sobre los mismos, a fin de que el que adquiere un inmueble pueda informarse del origen y extensión del derecho del enajenante.

En lo que atañe a los muebles, la reivindicación es harto limitada. Quien adquiere de buena fe un bien mueble, aún cuando el enajenante carezca de derecho para hacerlo, no está expuesto a la acción de reivindicación del verdadero propietario. Su buena fe lo protege, sin necesidad de que exista de por medio la publicidad (Art. 890 C. C. peruano; art. 2.279, par Io C. C. francés).

- La posesión de los inmuebles está respaldada por las acciones posesorias y los interdictos que se conceden al poseedor sea éste o no propietario. Por el contrario el poseedor de un bien mueble no tiene acceso a tales acciones, se entiende que su buena fe lo convierte en propietario. Nótese que el verdadero propietario de un bien mueble, que es desposeído injustamente, no puede recurrir a un interdicto para salvaguardar de inmediato su posesión que ha sido vulnerada. Tendrá que recurrir a una acción reivindicatoria que, como 
vimos es limitadísima. Y no estamos hablando de un lápiz o un libro, estamos hablando de un automóvil o una computadora, por ejemplo.

- La usucapión o prescripción adquisitiva distingue, para los inmuebles dos canales: con buena fe y justo título bastan 10 años de posesión; la mala fe y la falta de justo título obligan a una posesión de 30 años. En materia de bienes muebles la usucapión sólo interesa, en rigor cuando existe la mala fe, puesto que, como ya dijimos, el poseedor de buena fe de un bien mueble es automáticamente propietario. En este último caso se le da un rol determinante a un elemento tan subjetivo como la buena fe. De otro lado, el Código Civil peruano incurre en una contradicción mayúscula entre lo dispuesto en el art. 890 y lo reglamentado en el art. 893, al disponer un plazo prescriptorio para los bienes muebles cuando existe buena fe.

- Sólo pueden ser hipotecados los inmuebles no existiendo la hipoteca para los muebles que únicamente pueden ser objeto de prenda. Las naves y aeronaves si pueden hipotecarse, pero no en su condición de muebles, sino a mérito de la calidad inmobiliaria ficiticia que la ley les otorga.

En una época en que la economía se sustenta en el crédito y se requieren de garantias que respalden los préstamos que se solicitan, es inadmisible que una persona dueña de un patrimonio mobiliario se vea imposibilitada de obtener préstamos a través de una garantía hipotecaria. Cierto es que puede recurrir a la garantia prendaria, pero sabemos que esta es menos ventajosa y menos aceptable para ambas partes desde que una, el deudor, tiene que desposeerse del bien, y otra, el acreedor, tiene que cuidar del bien que se le entrega. Añádase que las más de las veces el hecho de entregar una cosa en prenda anula toda posibilidad de préstamo ya que dicha cosa puede ser la única fuente productora de ingresos con que cuenta el ciudadano y si ella es entregada le será imposible la obtención de ingresos para pagar el préstamo, en cuyo caso tendrá que optar por no pedirlo. 
Quien otorga un crédito busca seguridades para el pago y para ello solicita garantias que acrediten la solvencia del deudor. Sin embargo, hoy en día, insistimos, una persona que cuenta con un patrimonio mobiliario y que puede ser más solvente que un propietario de cosas inmuebles, no tendrá éxito, por ejemplo, ante un Banco o una financiera, debido a que la clasificación actual de los bienes no permite dar en hipoteca sino una cosa inmueble. Esto es aún más criticable en un país como el Perú en el que el acceso a la propiedad inmobiliaria constituye una especie de privilegio.

En suma la clasificación de que venimos hablando pone trabas para el acceso del crédito tan indispensable en sociedades como la nuestra. Este es otro de sus aspectos negativos.

d) La clasificación de las cosas en muebles e inmuebles es insuficiente porque no abarca a todos los bienes. En efecto, los derechos, esto es, los llamados bienes incorpóreos no pueden estar incluidos en la clasificación porque "la distinción de los bienes en muebles e inmuebles sólo se aplica a las cosas materiales. Unicamente tratándose de las cosas materiales se puede hacer la pregunta de si son o no susceptibles de desplazamiento" (11). Es un despropósito hablar de un derecho mueble o un derecho inmueble. Así como no podemos hablar del olor, color o sabor de un derecho no podemos hablar de su inmovilidad o de su posibilidad de traslado. Los derechos del autor, del artista o del inventor sobre la obra intelectual que han creado o sobre el invento que han hecho, son derechos que se comercian y que constituyen elaboraciones mentales, abstracciones que, evidentemente, nada tienen que hacer con un criterio referido a lo mueble o inmueble.

Sin embargo, la doctrina más generalizada y que mayor audiencia ha tenido, al incluir a los bienes incorporales "ha deformado el sentido de la distinción. Se puede decir que en adelante hay cuatro clases de bienes: $1^{\circ}$ los inmuebles propiamente dichos; $2^{\circ}$ los inmuebles incorporales; $3^{\circ}$ los muebles propiamente

(11) PLANIOL, op. cit. p. 36. 
dichos; y $4^{\circ}$ los muebles incorporales; siendo esta última clase de una importancia considerable, pues comprende todos los derechos de crédito, $\mathrm{y}$, por consiguiente toda la clase hoy de un valor económico incomparable, de títulos de Bolsa, fondos del Estado, acciones y obligaciones de sociedades, etc." (12).

Para darle cierta coherencia a este absurdo la doctrina o el uso han determinado que esta "división ordinariamente se hace atendiendo a la naturaleza de la cosa que constituye el objeto del derecho, y algunas veces también, solo por una elección arbitraria del Legislador" (13).

Situaciones como ésta se presentan cuando doctrina y legisladores haciendo gala de falta de criterio para conservar la esencia de las instituciones juridicas y dando muestrars también de falta de imaginación para encontrar soluciones que sin dejar de ser prácticas conserven la naturaleza juridica, prefieren forzar conceptos en un terco afán por hacerles actuar un libreto que no les corresponde.

Algunas legislaciones (Códigos Civiles alemán y suizo) con mejor sentido, al notar que la clasificación, como ya dijimos, se basta únicamente para las cosas corporales "se guardan bien de confundir en la misma categoría que los muebles propiamente dichos, los derechos de crédito, así como los otros bienes incorporales, tales como los oficios ministeriales, los derechos de propiedad literaria, artística, industrial, etc. Con esta clase de bienes, a los que no cabe aplicar la misma reglamentación que a los objetos muebles, forman, con razón, una tercera clase aparte, extraña a la división de las cosas en muebles e inmuebles" (14).

e) La clasificación no está planteada en términos juridicos. De acuerdo a lo ya estudiado, la distinción se basa (i) en criterios de naturaleza, o sea, las cosas se clasifican a partir de su condición fisica: si pueden o no trasladarse. Nótese que con este

(12) COLIN Y CAPITANT, op. cit. p. 465.

(13) PLANIOL, op. cit. p. 36.

(14) COLIN y CAPITANT, op. cit. p. 469. 
criterio se pudo haber elegido cualquier otno igualmente físico, igualmente "natural": el tamaño de las cosas o su color o su calidad de ásperas o lisas etc. o (ii) se basa en criterios económicos. Una cosa valiosa es inmueble aún cuando en la verdad de los hechos sea mueble y viceversa.

De manera que la clasificación tradicional se sustenta en criterios ajenos al Derecho, es decir, no tiene origen juridico, no es una elaboración de la doctrina, ha sido tomada de otros ámbitos y como tal tiene peculiaridades y contingencias que no tienen por qué guardar relación con el Derecho. En términos figurativos podemos decir que la clasificación es como un extranjero que en virtud de una nacionalización ha sido recibido por el Derecho, sin que esto signifique que quien lo acoge tenga que hacerle cambiar necesariamente sus costumbres. $\mathrm{Y}$ sin embargo, ella afecta en asuntos primoriales a las organizaciones juridicas, pues, a partir de la clasificación se determinan las formas de adquisición de propiedad y el tipo de garantía que pueden aplicarse a los distintos bienes, según sean éstos muebles o inmuebles. Todo con una clasificación postiza, sin estirpe, sin raíz juridica.

f) La clasificación no corresponde al mundo actual. Una clasificación de los bienes guarda estricta relación con la racionalidad de una época. No es un simple listado en el que se enumeran las cosas. Constituye un importantisimo fundamento para organizar a partir de ella las diferentes normas que regirán variados aspectos de un sistema legal. $\mathrm{Y}$ este sistema legal inevitablemente va a actuar sobre una determinada agrupación humana y, también inevitablemente, va a reflejar diferentes aspectos de esa sociedad. Queremos decir que una sociedad una vez constituida requiere de normas que regulen las relaciones entre las personas que la conforman, para ello recurre al Derecho y éste inexorablemente refleja la idiosincracia de ese grupo social en una época especifica. Esto significa que la opción que el derecho realize por tal o cual forma de clasificación de bienes guarda estrecha vinculación con la racionalidad de un momento histórico.

"Dentro de una sociedad de mercado, en la que los intercambios constituyen su ingrediente fundamental y donde las garantías de las transacciones deben ser muy seguras, el Derecho 
ha agrupado los bienes en función de su mayor o menor posibilidad para su transferencia -que guarda relación en los primeros tiempos de la sociedad de mercado con el valor del bien- y en función de la mayor o menor facilidad para entregar ftsicamente la cosa en garantia. Por consiguiente, no es una caracteristica natural del bien lo que constituye la base de la distinción sino la utilización sacial de ciertas caracteristicas naturales que realiza una cultura determinada" (15).

En esta linea de razonamiento cabe afirmar que la distinción entre muebles e inmuebles correspondió a formas de organización ya superadas. Sabemos que todo está en movimiento perpetuo y el quehacer jurídico no es ajeno a este fenómeno. Los Códigos y sus listados de cosas muebles y cosas inmuebles son colecciones de anticuarios que no se dan abasto para responder a los requerimientos actuales, "la clasificación legislativa acaba por anquilosarse en circulos cerrados y puede suceder, como de hecho ha sucedido, frente a un acelerado desarrollo económico-social, al que se contrapone la lentitud legislativa, mucho más si se trata de materias contenidas en códigos, que queden enumeradas entre las cosas en un tiempo entidades menores, aquellas que hoy tienen importancia igual, por no decir tal vez mayor, que las otras" (16).

Así acontece cuando se insiste en viejos conceptos para hechos nuevos; por eso, a riesgo de ser reiterativos insistimos en afirmar que la clasificación que se adopta en un tiempo refleja la racionalidad propia de una época y responde a los requerimientos de ese momento y no a los de después. Al respecto, reparemos en este magnífico párrafo de Vallet de Goytizolo que con gran acierto dilucida el asunto. "Cada pueblo en cada época refleja en una antitesis fundamental dos categorias de bienes a los que las respectivas condiciones sociales y económicas otorgan un rango de valoración distinto. Se refleja en su regulación jurídica que sujeta unos a la absorbente influencia de principios

(15) TRAZEGNIES, Fernando de, Bienes Naturaleza y Romanos, artículo publicado en "El Comercio", página Editorial, Lima, 21 de diciembre de 1982.

(16) BIONDI, Biondo, Los Bienes, Ed. Bosch, Barcelona 1961, p. 102. 
sociales y deja a los otros a las ltbres determinaciones individuales. En regimenes individualistas, la antítesis se refleja en más celosa vigilancia y tutela de los actos de enajenación, gravamen, cargas fiscales, etc., y mayor rigor en las formalidades de los negocios juridicos que tengan por objeto una de las dos categorias. Tal significación primordial presenta la clasificación cie bienes visibles $e$ invisibles en el antiguo pueblo griego; la casa, campo y huerto, en oposición a los otros bienes, en el Código de Hammurabi; los bienes reales y personales en el Derecho anglosajón; los bienes muebles e inmuebles en la fase heleno-oriental del Derecho romano. Ultima clasificación que dio nombre a la similar distinción del Derecho germánico y pasó luego a los derechos modernos de la Europa continental.

En tiempos modernos ha ido perdiendo fuerza lógica la clasificación total de los bienes en estas dos categorias de muebles e inmuebles. Han surgido nuevos bienes, como los de la propiedad intelectual o de la propiedad industrial, los títulos valores -que llegan a constituir ingentes montañas de valor-, los automóviles, las aeronaves, las empresas mercantiles. Su desenvolvimiento y desarrollo, emparejado con los progresos de la técnica, unido al apogeo de la maquinaria indusirial, ha hecho alcanzar a estos bienes muebles un valor e importancia jamás sospechados, no sólo intrínsecamente, sino como medios de producción en gran escala.

Ya no están justificadas las diferentes medidas de protección exigidas en la enajenación de inmuebles con respecto a ciertos bienes muebles, pertenecientes a los débiles juridicos. Tampoco aquel dualismo justifica hoy el encuadramiento de ciertos bienes muebles en el régimen traslativo genéricamente aplicado a éstos, ni aquella clásica diferenciación de los sistemas respectivos en cuanto a las formas transmisivas y de publicidad.

El legislador no puede olvidar que actualmente esos dos viejos moldes han sido desbordados por la cambiante realidad. Sin duda merecen todo el respeto a que son acreedores por la utilidad que han prestado al Derecho durante muchos siglos. Pero 
ya no bastan para satisfacer las necesidades de la vida juridica contemporánea" (17).

Definitivamente la decrépita clasificación, apoyándose en su antigua raigamble, se ha puesto a deambular entorpeciendo a nuestro Derecho en su labor normativa. $\mathrm{Ya}$ no es lo que ha sido aunque haya quienes deseen que siga siendo lo que fue.

Ante esta situación. ¿Qué es lo que debe hacerse? ¿Qué opción tomar? Con magnífica lucidez Fernando de Trazegnies opina que debemos abocarnos "al auténtico problema que se encuentra frente a nosotros: precisar lo más rigurosamente posible la distinción de bienes de acuerdo a la racionalidad propia de nuestra época (como también lo hicieron los romanos en su tiempo) y otorgarle los nombres adecuados a las nuevas clases (cualquiera que éstos sean). Pero lo importante es llamar a las cosas por sus nombres si no se quiere que nos perdamos en una jungla de lo imaginario constituida por el abuso de ficciones juridicas, en un mundo surrealista donde los bienes inmuebles se mueven y donde la entrega (traditio) consiste en no entregar nada. Intentar introducir a la fuerza los actuales criterios juridicos dentro de los viejos moldes puede resultar una solución semejante a la de cercenarle los pies al cadáver porque el muerto resultó demasiado grande para el ataúd que habia sido pedido de antemano" (18).

Hasta aqui este análisis. Consideramos que las razones expuestas demuestran suficientemente la inoperancia de la clasificación estudiada. Veamos ahora las legislaciones que la utilizan.

\section{CLASIFICACION DE LOS BIENES EN LA LEGISLACION PERUANA}

Hemos estudiado la clasificación que distingue las cosas muebles de las cosas inmuebles para demostrar su ineficacia. En esta

(17) VALLET DE GOYTIZOLO, Juan, Estudios sobre Garantías Reales, Ed. Montecorvo S. A. Madrid, 1973, p.p. 230 y 231.

(18) El Comercio, art. cit. 
parte vamos a analizar la legislación peruana para hacer notar que también es ineficáz por cuanto se basa en dicha clasificación. Entonces las críticas que ya hemos planteado se aplican todas al análisis que vamos a efectuar y como sería ocicso repetirlas, más bien, vamos a incidir en otras dos criticas fundamentales que aparecen de la legislación peruana, y que consisten en que la clasificación que atiende a la naturaleza de la cosa misma y diferencia entre muebles $e$ inmuebles, no permiite una adecuada organización de las garantias y no permite incorporar dentro de ella a todos los bienes sino sólo a parte de ellos.

Al desarrollar estas dos críticas podrá notarse como el legislador peruano ha actuado de modo errático en lo que se refiere a la clasificación de los bienes y a la organización de las garantías, asuntos que guardan estrecha relación y que tienen importancia en una sociedad moderna con economias que recurren fundamentalmente al crédito.

\section{Código Civil de 1852.-}

Este código utiliza 4 clases de clasificación:

1) Cosas Corporales

Cosas Incorporales

Art. $454^{\circ}$

2) Cosas Corporales

Muebles e Inmuebles

Art. $455^{\circ}$

3) Cosas Fungibles

Cosas No Fungibles

Art. $458^{\circ}$

4) Cosas Públicas

Cosas Comunes

Cosas Particulares

Art. 459:

Cosas de Culto

Cosas de Ninguno*

- A éstas el Código las define como "las que no están en propiedad de nadie o se hallan vacantes", mayúscula barbaridad. No existe nada que no tenga dueño, pues es el Estado, en última instancia, el duer̃o de aquello que no seria de nadie. 
De estas cuatro clasificaciones la única que tiene normas que la hacen utilizable es la de Muebles o Inmuebles. La existencia del resto de clasificaciones se entiende por la tendencia a definir que tuvo este Código, tendencia que lo llevó como acabamos de indicar, a plantear clasificaciones sin efectos (no existen normas que las implementen) y a confundir un Código con un texto universitario por la gran cantidad de definiciones y ejemplos que utiliza en muchos de sus artículos.

Veamos pues la clasificación principal. El art. 455 decia: "Las cosas corporales son muebles o inmuebles. Muebles, las que sin alteración pueden ser llevadas de un lugar a otro. Las demás son inmuebles.

Las semovientes se comprenden en los muebles".

De acuerdo a este artículo puede notarse que el criterio adoptado por el legislador es el romano. Ya hemos estudiado que en su origen la clasificación entre muebles o inmuebles no era más que una subdivisión de las cosas corporales porque sólo éstas eran capaces de movimiento o de fijeza.

Pero de inmediato el legislador quiebra el criterio que ha elegido. De algún modo intuye que la clasificación adoptada no es idónea, entonces en el art. 456 realiza una enumeración que en base a la ficción convierte a ciertos muebles en inmuebles. $\mathrm{y}$ distingue tres clases: inmuebles por naturaleza, por accesión y por destino. Declara que toda obra construida con adherencia al suelo para permanecer alli mientras dure es inmueble; de igual forma los frutos pendientes y las maderas antes de cortar, los ganados y demás objetos que hacen parte del capital de un fundo, las cañerias, herramientas, calderas, semillas y animales dedicados al cultivo, etc.

Subrayamos ganados y animales para resaltar más todavía la incoherencia de este Código, ya que en la parte final del art. 455 pese a haber definido a los muebles se preocupa de recalcar expresamente, redundantemente que los "semovientes se comprenden en los muebles", y sin embargo un articulo después, en el 456. convierte a los semovientes (ganado y animales de cultivo) en inmucbles. 
En suma, el Código 1852 utilizó, al clasificar a las cosas, una opción: el criterio de movilidad con ayuda de la ficción. Con el añadido de que su opción es incoherente, pues no existe explicación para lo señalado a propósito de los semovientes, o sea, ¿por qué insistió en decir que éstos eran inmuebles si de inmediato los iba a convertir en inmuebles?

Legislación defectuosa. Al hacer un listado de muebles que se convierten por mandato legal en inmuebles, se olvidó por completo de los derechos. Se olvidó de los créditos, sean títulos o valores, de los derechos de propiedad industrial, etc. en una palabra desdeñó la fortuna mueble; le dio todo su amparo a los inmuebles.

Esto se nota con más claridad en cuanto a las garantias. En el art. 1985 se define a la prenda como "la cosa mueble que se da en seguridad de una obligación contraida", y en el art. 2020 a la hipoteca como "el gravamen que se impone sobre un inmueble a favor de un tercero, en seguridad de un crédito o de una obligación".

Sólo existian garantias para las cosas corporales, sean muebles o inmuebles. Prenda, con entrega; hipoteca, con inscripción. No obstante en el art. 454 el legislador distinguió a las cosas corporales y las cosas incorporales para qué hizo esta clasificación si no iba dejar que accedan a las garantias las cosas incorporales? ¿qué quiso hacer? ¿simple academicismo? Tal vez. En todo caso este Código tuvo todos los defectos que hemos señalado respecto a la clasificación de muebles e inmuebles.

Su virtud es que mantuvo la naturaleza jurídica de las garantías, no cometió la torpeza de desnaturalizarlas, como se empezó a hacer desde 1916 con la ley 2402 que creó la prenda agrícola, prenda sin desplazamiento.

Quizás en descargo habria que decir que las insuficiencias del Código de 1852 no crearon mayores problemas. En ese entonces no habian aeronaves, automóviles y la marina apenas se bastaba para acciones de defensa territorial; el crédito con garantias de cosas muebles no era urgente. El vacío podia, de alguna manera, existir. 
Aunque, bueno es decirlo, esas carencias se harian manifiestas años después, con el código del 52 vigente, al tener que promulgarse la ley de hipoteca naval. Esto nos hace ver, además. que el legislador debe tener necesariamente una visión de futuro y una imaginación magnífica. Esta es su obligación más dificill.

\section{LAS LEYES ESPECIALES}

\section{a) Ley de Hipoteca Naval}

Estando vigente el criterio de moviliad que tenía el Código del 52, se promulgó el 30 de diciembre de 1916 la ley de Hipoteca Naval, que en su art. 1' determina: "Pueden ser objeto de hipoteca los buques mercantes con arreglo a las disposiciones de esta Ley. Para este sólo objeto se considerarán los buques mercantes como bienes inmuebles".

Hasta antes de esta ley los buques, cosas trasladables de un lugar a otro, eminentemente móviles, solo podian ser objeto de prenda lo que implicaba necesariamente su entrega y esto no tenía sentido, pues, el crédito solicitado no puede pagarse si la herramienta del trabajo no sigue en poder del deudor.

Toda vez que los buques son perfectamente identificables, tienen matricula, tienen registro y no son ocultables, cumplen los requisitos para ser hipotecados, se permitió se dictase la ley de hipoteca naval. Aqui el legislador introduce un cambio en la naturaleza de los bienes, no en la organización de las garantias ni en la naturaleza de las garantías sino en la naturaleza de los bienes. Pudo haber dicho otra cosa, por ejemplo, pudo decir los buques siguen siendo muebles pero sobre ellos se podrá constituir hipoteca. Eso habría significado cambiar el régimen de las garantias, plantear la hipoteca mobiliaria para no desnaturalizar la esencia de las garantias. No hizo eso, sino que los convirtió en inmuebles para los efectos de la ley y por consiguiente para los efectos de que pudiesen ser hipotecados. 


\section{b) Las leyes de prenda sin desplazamiento}

Contemporáneamente a la ley de Hipoteca Naval, el 13 de diciembre de 1916, se promulgó la ley 2402, que fue la primera ley de prenda sin desplazamiento, la prenda agrícola.

Se trata de una garantia para cubrir los préstamos solicitados por un agricultor o un ganadero, compuesta por los equipos de labranza, el ganado, y las cosechas. Como no puede haber entrega de los equipos de labranza porque sino ya el prestatario no necesita el préstamo se ideó la prenda sin desplazamiento que a tenor del art. $4^{\circ}$ de esta ley permite al deudor conservar la posesión de la cosa materia de la prenda en nombre del acreedor teniendo derecho a usarla.

En este caso no se cambió la naturaleza de los bienes, se cambió la naturaleza de las garantias. Se aceptó una prenda sin entrega estando vigente el art. 1985 del Código del 52, que indicaba como única prenda posible a la prenda con entrega -como debia ser- lo cual se hacia extensivo también a otra prenda vigente en ese momento, la prenda mercantil, regida por el Códidigo de Comercio y que también suponía desplazamiento.

Este cambio en la naturaleza de las garantias se repite cuando se dictan la ley $\mathrm{N}$ \% 7695 de 30 de enero de 1933, que crea la Prenda Industrial, el D. L. No 18880 de 8 de junio de 1971 que crea la prenda minera y el D. L. 23192 que crea la Prenda de Transporte con fecha 19 de julio de 1980 .

Son diversos momentos en los que el legislador acosado por las circunstancias que exigian normas a través de las cuales los propietarios de cosas muebles pudieran acceder al crédito dando en garantía a aquellas, empieza a crear prendas sin desplazamiento al encontrarse con Códigos Civiles, el del 52 y el del 36, que no se habían preocupado por este asunto, pese a que la realidad ya les habia mostrado esta necesidad, sobre todo a quienes redactaron el Código del 36. Preocupados por la tradición y los inmuebles, no cambiaron la clasificación de los bienes para permitir una correcta organización de las garantias. Por el contrario, propiciaron estas llamadas prendas sin desflazamiento, 
que consisten en una aberración, pues, atentan por completo contra la naturaleza juridica de las garantías.

Que solucionaron en parte los problemas presentados es cierto, pero el Derecho no es un oficio artesanal que recurre a soluciones empíricas. Es una ciencia que debe buscar soluciones a la vez prácticas y juridicas, capaces de solucionar los problemas sin atentar contra las Instituciones. Alli radica el talento del jurista y el arte del Derecho.

No fue así. La raiz del problema se encuentra en el persistènté afán de utilizar en la ley peruana, una clasificación que ya no es válida, que no responde a los requerimientos de nuestra sociedad.

\section{El Código Civil de 1936}

En este Código, el legislador abandona, en parte, el criterio de la movilidad. No lo hace totalmente porque el primer inciso del art. 819 dice que son muebles los bienes que pueden llevarse de un lugar a otro; mantiene entonces el criterio de la movilidad en parte, pero evidentemente no lo mantiene en todo porque en la enumeración que hace de los inmuebles, en el art. 812, incluye las naves, incluye las aeronaves, incluye los ferrocarriles. todos cosas móviles.

En vez de enfatizar en el criterio de la movilidad, como lo había hecho en el Código precedente, el legislador enumera, hace dos listas (art. 812 y 819) y coloca los bienes aparentemente $\in n$ función de las garantias, pues, coloca entre los inmuebles, los buques aviones y ferrocarriles con el propósito de que éstos puedan ser objeto de hipoteca y no de prenda.

Esta vez el legislador no cambia la naturaleza de las garantias porque mantiene la hipoteca sobre los inmuebles y la prenda con entrega sobre los muebles, cambia la naturaleza de los bienes y manteniendo la denominación de muebles o inmuebles abandona el criterio de la movilidad y recurre aparentemente a un próposito crediticio al organizar de alguna manera las garan- 
tias. Pero rápidamente advertimos que el legislador cometió algunas graves omisiones, porque las mismas razones que hacian que las naves, las aeronaves, los ferrocarriles fuesen inmuebles para el efecto de hipotecarlos, esas mismas razones regian para que los vehículos automotores también fuesen inmuebles y pudiesen ser hipotecados; son objeto de registro, son de difícil ocultamiento, apreciable valor económico, sin embrago, el legislador no lo hizo, con lo cual por la regla del primer inciso del art. 819 (son muebles los bienes que pueden llevarse de un lugar a otro) los vehiculos automotores, todos, automóviles, camiones, omnibuses, tractores y todos los demás son considerados hasta hoy muebles. Al punto de que hasta el 9 de julio de 1980 (fecha de promulgación del Decreto Ley № 23192 que creó la prenda de transportes, prenda sin desplazamiento) una empresa de transportes no podia afectar sus bienes porque no podia constituir hipoteca sobre sus omnibuses, pues no son inmuebles sino muebles. y tampoco podia constituir prenda porque habria tenido que entregar los vehículos cosa que no tiene sentido porque es su medio de trabajo y tampoco era posible constituir prenda sin desplazamiento porque no existia hasta ese momento la prenda de transporte, y sabemos, por el numerus clausus, que solo pueden constituirse los derechos reales expresamente autorizados por ley. En materia de prendas sin desplazamiento solo eran posibles tres: la minera, la agricola, la industrial; entre las cuales no estaba la de transportes.

Pero aún asi la solución no es buena, se insiste en utilizar una figura que atenta contra la naturaleza juridica de la prenda; y se cubre únicamente un aspecto, el de las empresas de transporte. ¿Por qué un particular no puede otorgar garantia con su automóvil sin desposeerse de él?

De otro lado el problema subsiste con los equipos de construcción. Las empresas constructoras, con excepción de sus vehículos que si hoy los podria prendar por razón de la prenda de transportes, mediante sus equipos no pueden otorgar hipoteca, prenda ni prenda sin desplazamiento.

Esto nos hace notar que optar por los listados además del riesgo de dejar fuera ciertas cosas, supone facultades adivina- 
torias ajenas a un jurista porque pueden ir surgiendo nuevos bienes conforme avanzan las sociedades, que podrian no estar integrados correctamente en la legislación vigente. Es preferible, por tanto, buscar criterios de clasificación más amplios, más adecuados desde que no todos los bienes son, necesariamente, muebles 0 inmuebles.

Una segunda critica que al inicio dijimos ibamos a desarrollar, es que la clasificación de los bienes inmuebles y muebles no cubre todos los bienes. Y no cubre, de manera muy simple, los bienes incorporales porque los bienes incorporales no son móviviles ni inmóviles; asi como no son rojos ni amarillos, los bienes incorporales, los derechos no son móviles ni inmóviles.

En via de ejemplo vamos a referirnos sólo al Código del 36. Ahí el legislador pese a todo, ha incluido en sus dos listas, en la de los inmuebles (art. 812) y en la de los muebles (art. 819) algunos bienes incorporales, v. gr., en materia de bienes inmuebles ha incluido en el inc. 7 las concesiones y autorizaciones para explotar servicios públicos. La concesión, un derecho de naturaleza administrativa, como el que tiene la Cía. Peruana de Teléfonos para explotar el servicio telefónico o ELECTROLIMA para el sistema de la luz en Lima, esas concesiones tienen carácter inmobiliario según este inciso del art. 812. También dice el inciso 8 que son inmuebles los derechos sobre inmuebles inscribibles en el Registro de la Propiedad, es decir, el derecho que tiene por ejemplo un condómino, que es una cuota-parte, incorporal, ese derecho es inmobiliario si es que el condominio recae sobre un inmueble, de tal suerte que el condómino puede por ejemplo hipotecar su cuota, su derecho.

Y en el art. 819 a propósito de los muebles el legislador también incluye algunos derechos, dice son muebles los derechos comprendidos en la propedad literaria $y$ artística y en la propiedad industrial, de este modo, todas las marcas, patentes, los derechos de un autor sobre una novela, tienen categoria mobiliaria y dice además los derechos referentes a muebles, dinero, servicios y a inmuebles si no son inscribibles en el Registro de la Propiedad. 
De manera que, como puede notarse, el legislador a pesar que los derechos no son móviles ni inmóviles haciendo tabla ras de la doctrina, ha incluído en su enumeración derechos, en una $y$ otra lista.

¿Cuál ha sido el criterio? Difícil saberlo. En el caso de los derechos sobre inmuebles la razón sería que el objeto mismo es inmueble entonces tiene una cierta lógica que el derecho que recae sobre un inmueble tenga también categoria inmobiliaria. Asi como el caso de los derechos sobre muebles también se comprende que si el objeto es una cosa mueble, entonces que el derecho que recae sobre él también sea mueble. ¿Pero por qué las concesiones para explotar servicios públicos son inmuebles? y ¿Por qué los derechos de la propiedad artística e intelectual e industrial son muebles? Eso no tiene una explicación. Allanamiento de la doctrina de un lado y de otro arbitrariedad del legislador, todo por mantener una clasificación que ya no puede más desde hace muchos años.

\section{CLASIFICACION DE BIENES EN LA LEGISLACION COMPARADA}

Recurrir a la legislación extranjera supone la posibilidad de encontrar diversas soluciones para variados aspectos. Se vuelve la mirada a otras latitudes para confrontar criterios buscando obtener soluciones nuevas o mejor estructuradas, tal vez una institución perfeccionada o quizá otra planteada de modo distinto; en fin, la idea que anima a revisar Códigos extranjeros es encontrar propuestas para lograr un mejor sistema jurídico.

En cuanto a la clasificación de los bienes no acontece así. Hemos venido sosteniendo que la clasificación de Bienes en muebles o inmuebles, es sumamente defectuosa, imperfecta y poco útil para las circunstancias actuales. Pues bien, toda la legislación extranjera, con la explicable excepción del Código Ruso, utiliza la clasificación de muebles e inmuebles.

El Código Civil francés en su art. 516 determina que "todos los bienes son muebles o inmuebles". De este modo comete el 
error que ya hemos indicado: considera a los derechos dentro de la clasificación y el supuesto criterio de movilidad no es mantenido, pues, si bien en el art. 517 se indica que "los bienes son inmuebles por su naturaleza..." de inmediato se agrega el elemento de ficción al decir "o por su destino o por el objeto al cual se aplican". En el caso de los muebles la situación es la misma, el art. 527 dice "los bienes son muebles por su naturaleza o por la determinación de la ley" (subrayado nuestro).

En cuanto al Código Civil alemán, no se dice explícitamente que la clasificación sea la de muebles o inmuebles, ya que el art. 90 prefiere hablar de "cosas (que) en el sentido de la ley son solamente las corporales", pero en los artículos siguientes se refieren a las cosas muebles indicando cuales son y cuando es que deben ser considerados como tales; o sea, que las cosas no son muebles en si sino en la medida en que la ley lo determine.

El Código Civil italiano habla de tres clases de Bienes. En el art. 812 define a los inmuebles con el mismo criterio del Código Francés: la naturaleza del bien, y además, la ficción. "Sono reputati inmobili" es la frase que utiliza: se reputan, se consideran como. No son, se consideran.

Luego en el art. 815, timidamente, esboza una distinción interesante, los bienes muebles inscritos en el Registro Público. Pero se limita a manifestar que están sujetos a sus propias disposiciones y supletoriamente a las disposiciones relativas a los bienes muebles. Este legislador sintió una especie de temor de variar esencialmente la clasificación tradicional y aunque intuyó que ciertos muebles por su importancia podian ser inscritos, con las consecuencias que de ello se derivan, prefirió eximirse y trasladar el problema a las disposiciones especiales.

Los arts. 615 y 715 del Código Civil Suizo también nos hacen ver con claridad la incoherencia tremenda que supone uttlizar el rótulo de movilidad para un contenido opuesto. Dice el Código Suizo: "son inmuebles dentro del sentido de la presente ley: 1) los bienes raices, 2) los derechos distintos y permanentes no matriculados en el registro". Los muebles, por supuesto, son los que "no están comprendidos en los inmuebles". 
En este, como en todos los Códigos es la ley la que determina la calidad de los bienes, pero, ésta determinación no busca, en esencia, discernir que es mueble o inmueble, busca, más bien, adaptar sus soluciones a los requerimientos de una sociedad, e incluyen en una clasificación a los derechos, a las semillas, a las colmenas de miel, o vuelven inmueble lo que en verdad es mueble, etc., etc. Cometen todos los disparates posibles con el plausible afán de adaptarse a los avances que se vienen sucediendo. pero sin detenerse a pensar que el asunto no está en insistir en la vieja clasificación sino en variarla por una que a la vez que resuelva el problema evite incurrir en una caricaturización de las Instituciones Juridicas.

Una muestra de esos equivocos es el Código Civil Español que en su art. 334 realiza una impresionante enumeración de bienes inmuebles -en el sentido de la ley- en un denodado esfuerzo por no dejar escapar algún bien, y pese a ello olvida a la maquinaria de construcción o los autobuses, por ejemplo, que sin duda pueden tener el "status" de un inmueble para que sus propietarios recurran al crédito usando de la hipoteca.

El Código Civil Japonés es el que más se acerca al criterio de movilidad que su clasificación anuncia, al afirmar en su art. 86 "El suelo y las cosas fijadas firmemente en él son inmuebles, todas las demás cosas son muebles". Y haciendo honor al origen de esta clasificación dice en su art. 85 "considérase cosas para los efectos de este Código a las cosas corpóreas". Si bien no quiebran el criterio de movilidad, dejan fuera a la propiedad incorporal; los derechos parecieran no existir para el derecho Japonés. Otra muestra de las insuficiencias de esta clasificación.

Analizar cada Código extranjero seria una labor reiterativa porque todos siguen la senda de la división clásica en muebles e inmuebles. En cada una de estas clases indican dos categorias: en primer lugar lo que llamariamos inmuebles y muebles por naturaleza y luego se refieren a los bienes que deben considerarse muebles o inmuebles para los efectos legales. En este sentido pueden revisarse los Códigos Civiles Méxicano arts. 750 , 752, 753, 754, 758 y 759; Brasileño arts. 43, 44, 47 y 48; Argentino arts. 2313, 2314, 2315 y siguientes; Boliviano, arts. 74 
y siguientes, pudiendo notarse que el art. 77 es copia del art. 815 del Código Italiano en lo referente a muebles sujetos a registro; Guatemalteco, arts. 442 y siguientes; y, en fin, el Proyecto del Código Brasileño, arts. 77, 78, 80 y 81 .

Es válido, pues, afirmar que el criterio usado en la legislación extranjera es el criterio de movilidad, al que se añade, ineludiblemente, el mandato legal, la ficción. Es un criterio mixto: el de la naturaleza de la cosa más la arbitrariedad legislativa. La razón no es oculta ni difícil de hablar: sola, la clasificación tradicional, no se da abasto y el legislador se ve compelido a buscar formas que la hagan útil y operativa. El Código Mexicano en su Exposición de Motivos reconoce que ha tenido que ampliar su listado de inmuebles por "los adelantos científicos $e$ industriales que han hecho aparecer nuevas clases de bienes".

Recurrir a ese tipo de solución es hacer del Derecho y de la labor legislativa, un ejercicio artesanal de una simpleza excesiva que, por añadidura, no requeriria de mayores conocimientos juridicos, sino apenas de un poco de sentido común.

Hasta el momento ningún Código extranjero se ha percatado que la solución no está en ampliar los listados sino en cambiar la clasificación porque de seguir el razonamiento mexicano, (común a todos los paises), ante cada avance económico o científico que haga aparecer nuevos bienes, tendrá que ampliarse el catálogo, lo que aparte de no solucionar el asunto, supone seguir avalando todas las deficiencias ya estudiadas, supone la reiteración de las ficciones y supone la tonteria de utilizar el nombre de una clasificación que no tiene nada que hacer con su contenido.

Hemos venido afirmando que la clasificación clásica debe ser sustituida. Esta situación debe ser hecha por una clasificación que no padezca de las debilidades ya explicadas en extenso.

Esto quiere decir que los "bienes sean agrupados correctamente en función de los fines que persigue la sociedad que usará ese derecho" (19).

(19) TRAZEGNIES, Fernando de, El Comercio, art. cit. 
Asimismo, que sea capaz de responder a los planteamientos económicos y sociales de la época actual manteniendo una necesaria coherencia jutidica; que agrupe a todos los bienes y que organice adecuadamente las garantias, tan necesarias en una economía basada en el crédito.

Consideramos que una clasificación regional seria una solución pertinente. Pero ese ya es otro tema y requiere de otra ocasión. 